\title{
Minimization of phosphate interference in the direct determination of arsenic in urine by electrothermal atomic absorption spectrometry
}

\author{
Zhe-ming $\mathrm{Ni}^{\mathrm{a}}{ }^{*}$, Zhu $\mathrm{Rao}^{\mathrm{b}}$, Mei $\mathrm{Li}^{\mathrm{b}}$ \\ ${ }^{a}$ Research Center for Eco-environmental Science, Chinese Academy of Sciences, PO Box 2871, Beijing 100085, China \\ ${ }^{\mathrm{b}}$ National Research Center for Geoanalysis, Beijing 100037, China
}

Received 1 April 1996; revised 11 June 1996; acceptcd 16 Junc 1996

\begin{abstract}
A direct method for the determination of arsenic in urine by Zeeman atomic absorption spectrometry has been proposed by graphite furnace atomization with $\left(\mathrm{NH}_{4}\right)_{3} \mathrm{RhCl}_{6}+$ citric acid as a mixed matrix modifier. Different matrix modifiers including palladium, nickel and rhodium, were used for the elimination of phosphate interference, which was most troublesome in the arsenic determination in urine. Rhodium was preferred to palladium and nickel; in its presence the determination of arsenic in urine can tolerate a char temperature of $1600^{\circ} \mathrm{C}$, a temperature high enough to drive off the urine matrix including calcium phosphate without losing arsenic. The citric acid in the furnace evolved active gases and carbon upon decomposition thus facilitating the creation of a favorable reducing environment for the formation of a $\mathrm{Rh}-\mathrm{As}$ alloy or intermetallic compounds which stabilized arsenic to a high temperature. In the determination of $1 \mathrm{ng}$ of arsenic, $1.0 \mathrm{mg} \mathrm{ml}^{-1}$ phosphate in the form of calcium phosphate can be tolerated. Analytical results obtained for standard urine sample compared ( $>92 \%$ recovery) well with the certified value. The lowest concentration of arsenic that could be determined was $20 \mathrm{ng} \mathrm{ml}^{-1}$ in the undiluted urine.
\end{abstract}

Keywords: Arsenic in urine; Atomic absorption spectrometry; Rhodium as matrix modifier; Zeeman background correction; Phosphate interference

\section{Introduction}

In biological samples arsenic is usually present in a matrix containing an excessive amount of phosphorus. For instance, mussel has a phosphorus content $10^{3}$-fold greater than that of arsenic and human urine is rich in phosphate. Phosphate buffers have been used as mobile phases in ion exchange and

\footnotetext{
* Corresponding author. Fax: 86102555381
}

liquid chromatography in the separation of arsenic species [1]. Therefore, the determination of arsenic in the presence of phosphate is of practical interest. However, the interference of phosphate on arsenic determination in the graphite furnace has been well documented [2-4]. According to Fernandez and Giddings [2], this interference was supposed to be due to the calcium phosphate in the sample which produced $\mathrm{PO}$ or $\mathrm{P}_{2}$ during thermal decomposition and the interference was eliminated when Zeeman background correction was used. In contrast, other 
workers found that the PO band was effected by a magnetic field [5-7]. Ohlsson and Frech [8] were able to ascertain the presence of $\mathrm{PO}$ in the graphite tube during vaporization of a phosphate-containing matrix and showed that PO band absorption was effected by a magnetic field with the use of time-resolved highresolution spectrographic measurements. For the elimination of phosphorus interference on arsenic determination, Bauslaugh et al. [3] found that the addition of $\mathrm{Ni}$ and $\mathrm{Pt}$ has a significant effect on the formation of gaseous phosphate decomposition products thereby decreasing the spectral interferences at As resonance lines. The interference is troublesome; according to Welz [4], in the presence of palladium phosphate at a concentration of $50 \mathrm{mg} \mathrm{l}^{-1}$ in the form of $\mathrm{CaHPO}_{4}$ decreased the arsenic signal to about $75 \%$ of that obtained in the absence of phosphate. This is due most probably to a nonspectral interference, because there is no visible baseline distortion and the interference was also observed in an instrument with Zeeman background correction.

The problem of phosphate interference arsenic determination needs further study. The aim of the present work is to devise a method for the minimization of phosphate interference. This is achieved by using $\left(\mathrm{NH}_{4}\right)_{3} \mathrm{RhCl}_{6}+$ citric acid which was found to be capable of stabilizing arsenic in urine to a temperature as high as $1600^{\circ} \mathrm{C}$, thus allowing the urine matrix to be eliminated. The method has been applied to the analysis of urine containing not less than $20 \mathrm{ng} \mathrm{ml}^{-1}$ arsenic.

\section{Experimental}

A Hitachi Z-8200 Polarized Zeeman Atomic Absorption Spectrometer equipped with a GA-3 graphite furnace was employed for all analyses. Acquisition and treatment of data were performed with an IBM compatible 80386 computer and Z-8200 windows-base application software. Data and absorbance were output though a Brother M-2724 printer. Pyrolytically coated graphite tubes (Beijing Research Institute of Materials and Technology, Ministry of Astronautics) were used. The internal gas flow was interrupted during the atomization cycle. Integrated absorbance was measured in all experiments.
Table 1

Furnace program for As in urine with $\left(\mathrm{NH}_{4}\right)_{3} \mathrm{RhCl}_{6}+$ citric acid

\begin{tabular}{llrllll}
\hline $\begin{array}{l}\text { Stage } \\
\text { no. }\end{array}$ & Stage & \multicolumn{2}{c}{ Temperature $\left({ }^{\circ} \mathrm{C}\right)$} & Ramp (s) & Hold (s) & $\begin{array}{l}\text { Gas flow } \\
\left(\mathrm{ml} \mathrm{min}^{-1}\right)\end{array}$ \\
\cline { 2 - 5 } & & Start & End & & \\
\hline 1 & Dry & 50 & 140 & 10 & 30 & 200 \\
2 & Ash & 200 & 1600 & 10 & 30 & 200 \\
& & & $1400^{\mathrm{a}}$ & & & \\
3 & Atom & 2600 & 2600 & 0 & 10 & 0 \\
4 & Clean & 2600 & 2600 & 0 & 4 & 200 \\
5 & Cool & & & & 5 & 200 \\
\hline
\end{tabular}

${ }^{\mathbf{a}}$ For As in standard solution.

A high intensity arsenic hollow cathode lamp from the General Research Institute for Non-ferrous Metals, Beijing, China, operated at $6 \mathrm{~mA}$, was used. The wavelength and slit width were set at 193.7 and $1.3 \mathrm{~nm}$, respectively.

The furnace program is listed in Table 1.

\subsection{Reagents}

Doubly distilled water was used throughout.

An arsenic stock solution of $1 \mathrm{mg} \mathrm{ml}^{-1}$ was prepared by dissolving $0.1320 \mathrm{~g}$ of $\mathrm{As}_{2} \mathrm{O}_{3}$ in $50 \mathrm{ml}$ of $0.5 \mathrm{M} \mathrm{NaOH}$ with warming. After cooling, $3 \mathrm{ml}$ of $12 \mathrm{M} \mathrm{HCl}$ was added and diluted to $100 \mathrm{ml}$ with water. Working solutions were prepared by serial dilution of the stock solution immediately before use.

A rhodium solution containing $2.5 \mathrm{mg} \mathrm{ml}^{-1} \mathrm{Rh}$ was prepared by dissolving ammonium hexachlororhodate(III) $\left(\left(\mathrm{NH}_{4}\right)_{3} \mathrm{RhCl}_{6} \cdot 1.5 \mathrm{H}_{2} \mathrm{O}\right.$, extrapure, Tianjin) in water.

A palladium solution containing $2.5 \mathrm{mg} \mathrm{ml}^{-1} \mathrm{Pd}$ was prepared by dissolving palladium sponge powder (Light, UK) in concentrated $\mathrm{HNO}_{3}$ with a few drops of $\mathrm{HCl}$ and evaporating to near dryness. The palladium salt was dissolved in $0.1 \mathrm{M} \mathrm{HNO}_{3}$ and diluted to volume.

A nickel solution containing $2.5 \mathrm{mg} \mathrm{ml}^{-1}$ nickel was prepared by dissolving $\mathrm{Ni}\left(\mathrm{NO}_{3}\right)_{2} \cdot 6 \mathrm{H}_{2} \mathrm{O}$ (Merck; Darmstadt, Germany, extrapure) in water.

Citric acid solution (Beijing Chemical Works, Analytical Reagent), $120 \mathrm{mg} \mathrm{ml}^{-1}$, was prepared by dissolving the acid in water.

Ammonium dihydrogenphosphate solution (Beijing Chemical Works, Analytical Reagent), $10 \mathrm{mg} \mathrm{ml}^{-1}$, was prepared by dissolving the salt in water. 
Calcium nitrate solution, $10 \mathrm{mg} \mathrm{Ca}^{2+} \mathrm{ml}^{-1}$, was obtained by dissolving calcium carbonate (standard material from National Research Center for Certified Reference Materials) in dilute nitric acid.

The phosphate and calcium solutions were mixed in a mole ratio of $\mathrm{PO}_{4}^{3+}: \mathrm{Ca}^{2+}=1: 0.6$ before use. The phosphate was added in the form of calcium phosphate.

All chemicals were of analytical reagent grade in which no arsenic was detected.

\section{Results and discussion}

\subsection{Comparison of modifiers for the suppression of calcium phosphate interference}

The most commonly used matrix modifier for stabilizing relatively volatile elements is palladium [9]. However, Welz et al. [4] found that in the presence of palladium loss of arsenic occurred even at a low phosphate concentration of $5 \mathrm{mgl}^{-1}$. Saeed and Thomassen [10] indicated that the addition of a large amount of nickel to a sample containing phosphate suppressed the non-spectral absorption signal. Nickel obviated the spectral interference by converting phosphate into free atoms. Bauslaugh et al. [3] found that a mixed matrix modifier of $0.1 \%$ $\mathrm{Ni}+2.5 \% \mathrm{Pt}$ in $3 \mathrm{M} \mathrm{HNO}_{3}$ effectively controlled the spectral interference found at the As resonance line. The amount of platinum added was excessive and the furnace will not tolerate the high acid concentration used [11]. Edgar and Lum [12] proposed the use of $5 \%$ nickel nitrate to eliminate the phosphate interference on arsenic in urine. This requires the addition of $100 \mu \mathrm{g}$ of nickel when $10 \mu \mathrm{l}$ of sample was injected into the furnace. The excessive amount of $100 \mu \mathrm{g}$ of nickel added will contaminate the tube and graphite ring and will certainly shorten the lifetime of the graphite tube.

To compare the effect of different modifiers palladium, nickel and rhodium on the minimization of phosphate interference on arsenic determination, experiments were carried out using $25 \mu \mathrm{g}$ of the modifiers. The recoveries of arsenic are depicted in Fig. 1. With nickel the recovery of arsenic decreases to $89 \%$ when $250 \mu \mathrm{g} \mathrm{ml}^{-1}$ phosphate in the form of calcium phosphate is present. Palladium shows a

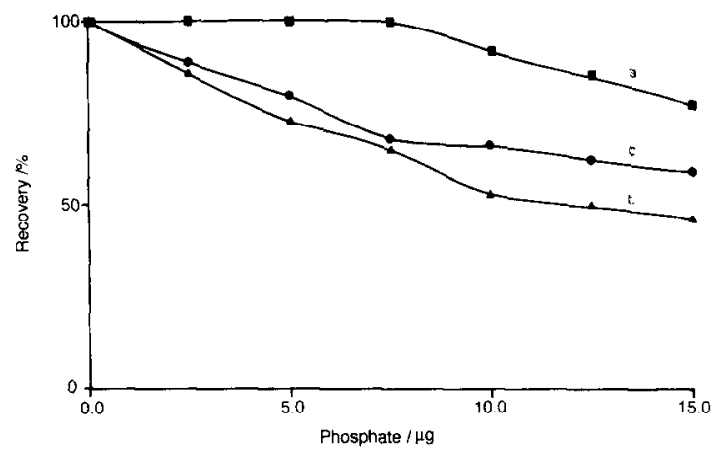

Fig. 1. Effect of phosphate on the recovery of $1.0 \mathrm{ng}$ of As in the presence of $25 \mu \mathrm{g}$ of different modifiers. (a). $\mathrm{Rh}$ as $\left(\mathrm{NH}_{4}\right)_{3} \mathrm{RhCl}_{6}$ and $1.2 \mathrm{mg}$ of citric acid; (b) $\mathrm{Pd}$; (c) $\mathrm{Ni}$ pyrolysis $1400^{\circ} \mathrm{C}$, atomization $2600^{\circ} \mathrm{C}$

similar effect, a recovery of $85 \%$ being found in the presence of the same amount of phosphate. The result is better than that reported by Welz et al. [4]. Rhodium gives more favorable results, $1000 \mu \mathrm{g} \mathrm{ml}^{-1}$ phosphate can be tolerated when $25 \mu \mathrm{g}$ of rhodium in the form of $\left(\mathrm{NH}_{4}\right)_{3} \mathrm{RhCl}_{6}$ and $1.2 \mathrm{mg}$ of citric acid are added. The arsenic peak profile does not change much when $500 \mu \mathrm{g} \mathrm{ml}^{-1}$ phosphate is introduced (Fig. 2(a)), but significant changes in arsenic peak profiles are observed with palladium or nickel (Fig. 2(b) and (c)). In the presence of phosphate, the peak profile for arsenic in palladium becomes much broader probably due to the stabilizing effect of phosphate on arsenic (Fig. 2(b)(2)). Arsenic with nickel in phosphate seems to give rise to two peaks, perhaps due to a more complicated mechanism of atomization such as formation of two different arsenic compounds prior to atomization.

Rhodium is therefore preferred to palladium or nickel in suppressing the phosphate interference. The rhodium compound used was ammonium hexachlororhodate(III) which is water soluble and convenient to prepare. In order to remove the chloride in the compound citric acid was added. The chloride present may cause the volatilization of $\mathrm{AsCl}_{3}\left(\right.$ bp $130^{\circ} \mathrm{C}$ ) leading to the loss of arsenic signal. With the addition of citric acid the chloride will be replaced by citrate and $\mathrm{HCl}$, which has a large dissociation energy of $427 \mathrm{~kJ} \mathrm{~mol}^{-1}$ and is stable in the high temperature environment, will be liberated [13]. Only $100 \mu \mathrm{g}$ of citric acid is needed for $25 \mu \mathrm{g}$ of $\mathrm{Rh}$ to obtain a steady 

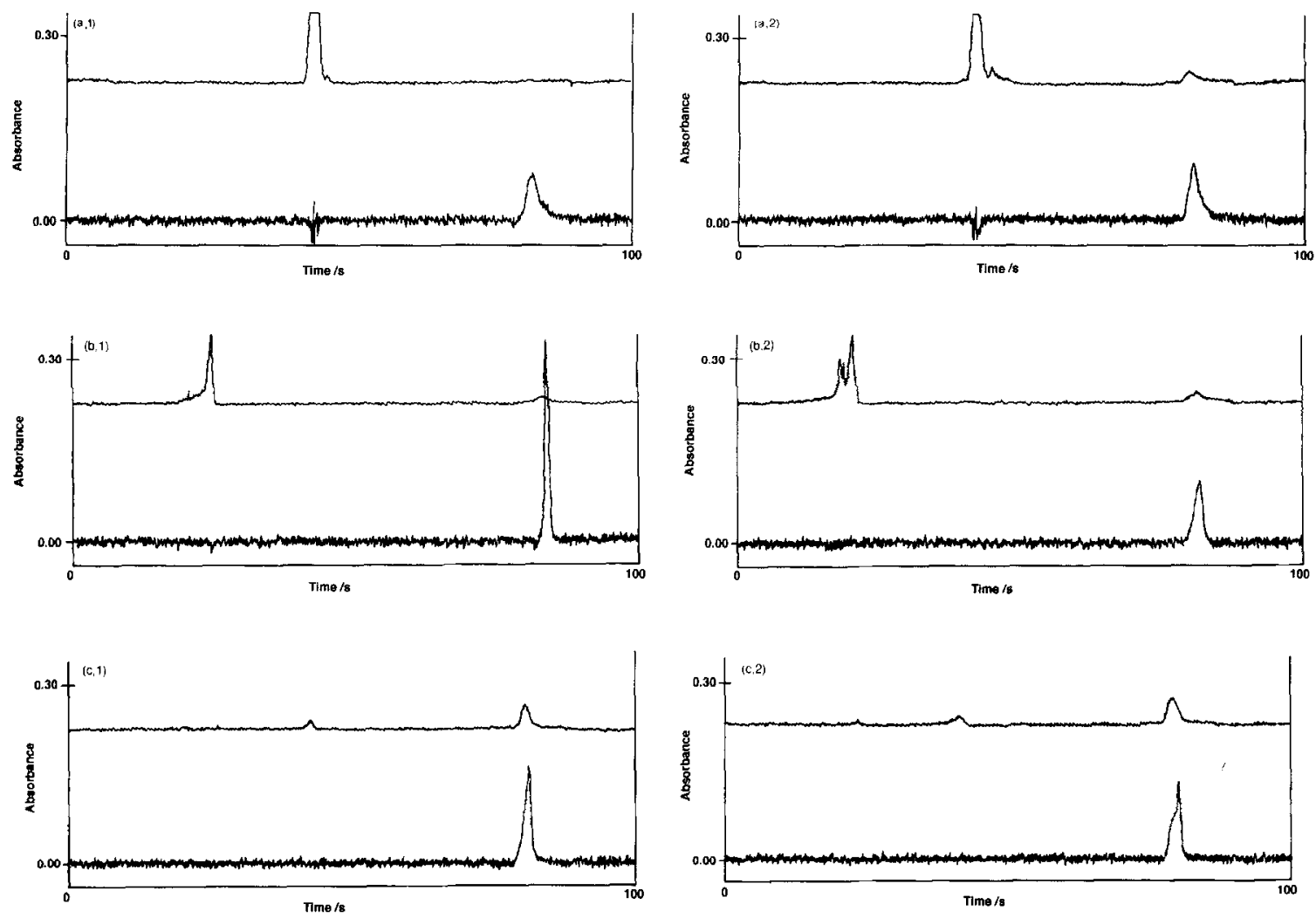

Fig. 2. Peak profiles for $1.0 \mathrm{ng}$ of As in the presence of (a) Rh, (b) Pd, and (c) Ni. (1) without addition of phosphate; (2) with addition of $5 \mu \mathrm{g}$ of phosphate in the form of calcium phosphate Integrated absorbance for As: without phosphate (a) $0.2440 \mathrm{~s}$, (b) $0.2355 \mathrm{~s}$, (c) $0.2499 \mathrm{~s}$; with phosphate (a) $0.2290 \mathrm{~s}$, (b) $0.1738 \mathrm{~s}$, (c) $0.2054 \mathrm{~s}$. upper curve : background absorption; lower curve: absorption profile of As.

absorbance signal for $1 \mathrm{ng}$ of arsenic (Fig. 3). An excess amount of $1.2 \mathrm{mg}$ of citric acid was introduced into the furnace to ensure the elimination of interference from any chloride that might be present in the sample. The presence of the organic reagent has the further advantage of creating a more favorable reducing environment in the furnace. The organic ligand evolves active gases $\left(\mathrm{CO}+\mathrm{H}_{2}\right)$ and produces active carbon [14], thus enhancing the reduction of arsenic and rhodium to the elements in highly dispersed forms and promoting the formation of a Rh-As alloy or intermetallic compounds. The pyrolysis curve for arsenic in the presence of ammonium hexachlororhodate and citric acid is shown in Fig. 4(a). It is interesting to find that arsenic can be stabilized up to a temperature of $1400^{\circ} \mathrm{C}$. The higher pyrolysis temperature arsenic can tolerate, the less will be the interference effect. Subsequent experiments were carried out using

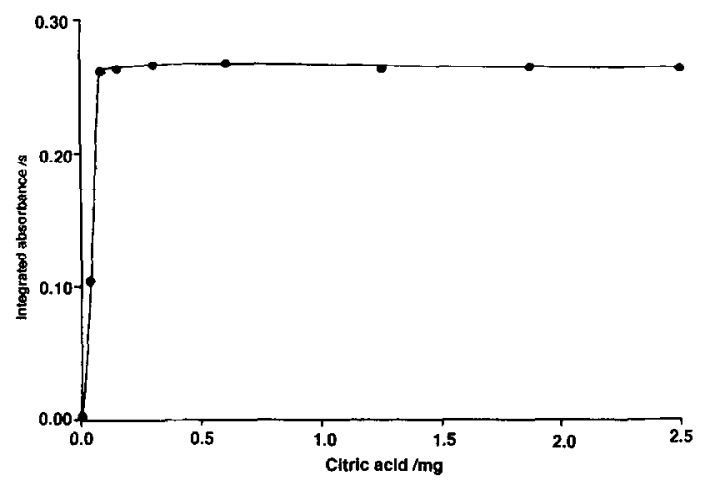

Fig. 3. Effect of citric acid on the integrated absorbance of $1.0 \mathrm{ng}$ for $\mathrm{As}$ in the presence of $25 \mu \mathrm{g}$ of $\mathrm{Rh}$ as $\left(\mathrm{NH}_{4}\right)_{3} \mathrm{RhCl}_{6}$ (pyrolysis $1400^{\circ} \mathrm{C}$, atomization $2600^{\circ} \mathrm{C}$ ).

$\mathrm{Rh}+$ citric acid as a mixed modifier for stabilizing arsenic and removing phosphate interference in human urine. 


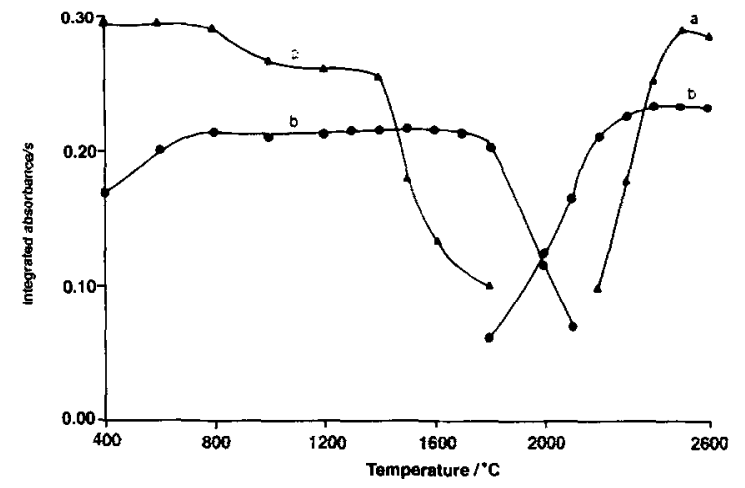

Fig. 4. Pyrolysis and atomization curves for $1.0 \mathrm{ng}$ of As in the presence of $25 \mu \mathrm{g} \mathrm{Rh}$ as $\left(\mathrm{NH}_{4}\right)_{3} \mathrm{RhCl}_{6}$ and $1.2 \mathrm{mg}$ of citric acid Left branch: pyrolysis curves for (a) $1.0 \mathrm{ng}$ of As and (b) 1.0 ng of As in urine diluted $(1+4)$; atomization at $2600^{\circ} \mathrm{C}$. Right branch : atomization curves for (a) $1.0 \mathrm{ng}$ of As; pyrolysis at $1400^{\circ} \mathrm{C}$; (b) $1.0 \mathrm{ng}$ of As in urine $(\mathrm{l}+4)$, pyrolysis at $1600^{\circ} \mathrm{C}$.

\subsection{Analysis of urine}

The direct determination of arsenic in urine was found to be virtually impossible with or without nickel matrix modification as summarized by previous workers $[15,16]$. In the presence of nickel the suppression was about $30 \%$ and $50 \%$ at $10-$ and 3 fold dilution, respectively. The detection limit was $50 \mathrm{ng} \mathrm{ml}^{-1}$. Even with the addition of a large amount of nickel ( $5 \%$ nickel nitrate solution), the recovery was variable ranging from $48 \%$ to $80 \%$ despite using Zeeman background correction. Since a mixture of ammonium hexachlororhodate and citric acid was found to be efficicnt in overcoming the phosphate interference, it was expected that this modifier could be applied for the determination of arsenic in urine. The pyrolysis curve of arsenic in urine was constructed by setting the atomization temperature at $2600^{\circ} \mathrm{C}$ and the atomization curve was obtained by keeping the pyrolysis temperature at $1600^{\circ} \mathrm{C}$, as preliminary experiments had shown that this temperature can be tolerated by arsenic in urine. The results are depicted in Fig. 4(b). The tolerated pyrolysis temperature in urine of $1600^{\circ} \mathrm{C}$ was higher than that in a standard solution probably due to the presence of phosphate in urine. When $5 \mu \mathrm{g}$ of phosphate was added to a standard arsenic solution, the tolerated pyrolysis temperature increased from $1400^{\circ} \mathrm{C}$ to $1600^{\circ} \mathrm{C}$. When atomization was carried out in the temperature range $2400-2600^{\circ} \mathrm{C}$, arsenic gave similar absorbance values, but the absorption peak was broader and less symmetrical when the temperature was kept below $2500^{\circ} \mathrm{C}$. In urine analysis, $10 \mu 1$ of freshly collected urine (diluted 1+4) was introduced into the furnace together with $10 \mu \mathrm{l}$ each of $0.25 \%$ rhodium solution in the form of ammonium hexachlororhodate and $12 \%$ citric acid. The furnace program is listed in Table 1.

\subsection{Analytical performance}

The characteristic mass which gave an integrated absorbance of $0.0044 \mathrm{~s}$ was found to be $18 \mathrm{pg}$ of As in urine diluted $(1+4)$. An absolute detection limit $(3 \sigma)$ of $25 \mathrm{pg}(n=9)$ was found in the urine $(1+4)$ which resulted in a detection limit of $6.3 \mathrm{ng} \mathrm{ml}^{-1}$ in undiluted urine.

Recoveries for $50-100 \mu \mathrm{g} \mathrm{ml}^{-1}$ As added to urine sample $(1+4)$ were found in the range $92-96 \%$ with a standard deviation of $4 \%$. The regression equation for the calibration curves for standard arsenic and arsenic in urine $(1+4)$ were $y=0.2212 x+0.0114$ and $y$ $=0.2361 x+0.00625$ with correlation coefficients of 0.9989 and $0.9999(n=6)$, respectively, where $x=$ analyte mass (ng) and $y=$ integrated absorbance.

Results for real sample analysis are summarized in Table 2. The frozen urine GBW09102 is a Standard Reference Material certified by Beijing Medical School using various analytical techniques including flame atomic absorption spectrometry, inductively coupled plasma-mass spectrometry, neutron activation analysis and anodic stripping voltammetry. Samples $1-4$ were freshly collected from volunteers in this laboratory. Samples 3 and 4 were obtained

Table 2

Determination of As in human urine

\begin{tabular}{llll}
\hline Sample & \multicolumn{2}{l}{ Concentration of As $\left(\mathrm{ng} \mathrm{ml}^{-1}\right)$} & $\begin{array}{l}\text { Recovery of } \\
\text { As }(\%)^{\mathrm{b}}\end{array}$ \\
\cline { 2 - 3 } & Found $^{\mathrm{a}}$ & Reference value & \\
\hline Frozen urine & & & \\
GBW09102 & $28 \pm 2$ & $20 \pm 6$ & $93 \pm 4$ \\
1 & $37 \pm 7$ & - & $92 \pm 3$ \\
2 & $48 \pm 2$ & - & $96 \pm 4$ \\
3 & $81 \pm 11$ & - & - \\
4 & $106 \pm 15$ & - & - \\
\hline
\end{tabular}

${ }^{a}$ mean \pm standard deviation $(n=5)$.

${ }^{b}$ mean \pm standard deviation $(n=3)$. 

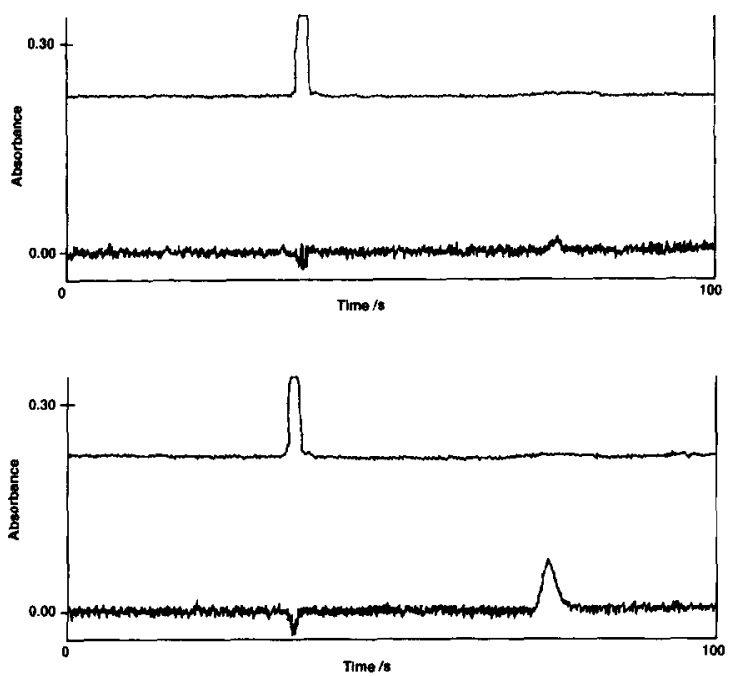

Fig. 5. profiles of (a) $0.18 \mathrm{ng}$ of As in $20 \mu \mathrm{l}$ of urine $(1+4)$ corresponding to $45 \mathrm{ng} \mathrm{ml}^{-1}$ in undiluted urine; integrated absorbance $0.0364 \mathrm{~s}$; (b) a spiked of $1.0 \mathrm{ng}$ of As in $20 \mu \mathrm{l}$ of urine $(1+4)$; integrated absorbance $0.2305 \mathrm{~s}$. pyrolysis $1600^{\circ} \mathrm{C}$, atomization $2600^{\circ} \mathrm{C}$; upper curve: background absorption lower curve: absurption profile of As.

from individuals not exposed to arsenic through occupation; the high levels of arsenic found probably originated from seafood. Since no detectable amount of As can be found in the reagents, the sensitivity can further be improved by successive double introduction of the urine sample $(1+4)$ into the furnace, the first injection being followed by the second after drying and charring. Fig. 5 presents the absorption profiles for arsenic in a urine sample $(1+4)$ with and without addition of $1.0 \mathrm{ng}$ of As.

\section{Conclusion}

The proposed method has the advantage of specificity and speed of measurement and may serve as a monitor of recent arsenic exposure. Since no chemical pretreatment is required, the analyzed sample solution is free from contamination as acids usually contain detectable amounts of arsenic. The technique can be used for the direct determination of trace arsenic in urine or other biological fluids containing arsenic levels not less than $20 \mathrm{ng} \mathrm{ml}^{-1}$.

\section{Acknowledgements}

This work was supported by Chinese Academy of Sciences. The authors thank Beijing Hitachi Scientific Instrument Laboratory for the loan of Z-8200 atomic absorption spectrometer.

\section{References}

[1] M. Morita, T. Uehiro and K. Fuwa, Anal. Chem., 53 (1981) 1806.

[2] F.J. Fernandez and R. Giddings, At. Spectrosc., 3 (1982) 61.

[3] J. Bauslaugh, B. Radziuk, K. Saeed and Y. Thomassen, Anal. Chim. Acta, 165 (1984) 149.

[4] B. Welz, G. Schlemmer and J.R. Mudakavi, J. Anal. At. Spectrom., 3 (1988) 695.

[5] G.R. Carnick, W. Barnett and W. Slavin, Spectrochim. Acta, Part B, 41 (1986) 991.

[6] D. C Manning and W. Slavin, Spectrochim. Acta, Part B, 42 (1987) 755 .

[7] G. Wibetoe and F.J. Langmyhr, Anal. Chim. Acta, 198 (1987) 81.

[8] K.E. Anders Ohlsson and W. Frech, J. Anal. At. Spectrom., 4 (1989) 379.

[9] Ni Zhe-ming and Shan Xiao-quan, Spectrochim. Acta, Part B, 43 (1988) 937.

[10] K. Saeed and Y. Thomassen, Anal. Chim. Acta, 130 (1981) 281.

[11] K.S. Subramanian, J.C. Meranger, C.C. Wan and A. Corsini, Int. J. Environ. Anal. Chem., 19 (1985) 261.

[12] D.G. Edgar and K.R. Lum, Int. J. Environ. Anal. Chem., 16 (1983) 219 .

[13] W. Slavin, G.R. Carnrick and D.C. Manning, Anal. Chem., 56 (1984) 163.

[14] E. Tserovsky, S. Arpadjan and I. Karadjova, Spectrochim. Acta, Part B, 47 (1992) 959.

[15] K.S. Subramanian, Prog. Analyt. Spectrosc., 11 (1988) 511.

[16] F. Puttemans and D.L. Massart, Mikrochim. Acta, 1 (1984) 261 . 